tion. For a detailed study the reader is referred to the individual chapters of the contributors themselves. As a result of assembling this collection the editors hope to have helped towards the development of a conceptualization of the different aspects and conditions of the international practice of law. There is of course more than one approach and more than one strategy to cope with globalization in the area of the international practice of law. The various options have different consequences. It was not so much the goal to assemble this collection in order to have a definite answer as to invite questions and to try to gain material that could then be used in the ongoing process of reacting to the challenges of the international practice of law.

23.) As Lloyd N. Cutler points out in his foreword ante, there is a need for permanent basic legal education for all lawyers whether they specialize in local or in international law. In times of globalization, basic legal education means a sound understanding and appreciation of international, transnational and comparative legal issues combined with the development of the appropriate means to acquire knowledge of languages and of the capability to express and exchange ideas and views. Lloyd $\mathrm{N}$. Cutler confronts this internationally educated lawyer with a series of cited questions asked by the contributors to this collection: «Are the ... changes inevitable? Are the developments ... good for clients ... lawyers ... for the practice of law? Are they good for the development of the law itself, for the society, for the international community of nations? If not, what could be better, what can we do to move ... in the right directions?m.

24.) Klaus Böhlhoff, the other eminent lawyer who honours this collection with a foreword ${ }^{10}$ sees the world's legal profession going through an intense international education due to an increased globalization demand for international legal advice. He points out the difference between the glittering international practice of law and the still impressive number of lawyers (e.g., more than 90 per cent of all German lawyers) working in small firms or as sole practitioners"1.

25.) It is the intention of the editors of this book to contribute to the awareness of the legal profession. The members of the community of the international practice of law may be interested in the deep and detailed insights provided by known specialists in the various subjects in which legal managerial and technical developments form new cutting edges. The less globally active lawyers may like to take note of the general principles and big tendencies described by authors with a reputation for broad and wide thinking.

10 See K. Böhlhoff, (Foreword) ante.

1 Lloyd N. Cutler and Klaus Bshlhoff are certainly in agreement with the summary made by Professor HansJurgen Hellwig, Vice-President of the German Bar Association, in his presentation to the Council of the International Bar Association in Versailles, France on 20 May 2000 on «Professionalism versus Commercia lismo\%. Professor Hellwig discussing the task of lawyers said "i it would be idenl if the lecal profession could make society aware of the development of the globalization and the reasons thereforem. Professor Hellwis himself concluded that this would be too over ambitious a goal and he therefore at least asked for tolwis be aware of the development in the leal system and is dan

\section{Managing the International Law Firm: Nuisance or Necessity?}

Günter Müller Stewens ${ }^{2}$ and Jens Drolshammer ${ }^{3}$

I. Introduction

II. From Law Office to Law Firm? 500

III. New Strategies for Law Firms 503

a) Diversification and Specialization 503

b) External Growth $\quad 505$

c) Intensification of Competition $\quad 507$

IV. The Business Model 508

a) Value Generating Activities $\quad 509$

b) Shifts of emphasis in growth 511

V. Organization 512

a) Governance $\quad 513$

b) Management dimensions $\quad 513$

c) Responsibility for Results and Distribution of Power 516

$\begin{array}{ll}\text { d) Culture } & 517\end{array}$

VI. Summary and Prospects $\quad 518$

Bibliography $\quad 520$

Erstmals veroffentlicht in: The Internationalization of the Practice of Law, 2001, Kluwer Law International, The Haguc, London, Boston, 2001, S. 203-227, mit Günter Müller-Stewens.

Professor of Management and Organization at the University of St. Gallen; Managing Disector of the Institute of Management.

3 Professor of Law, (Titularprofessor für Angloamerikanisches Recht und Rechtsgeschüftsplanung und -gestaltung), University of St. Gallen, Swizzerland; Co-Founder and President of the Commission and Lecturer on Law, Master of European and Intemational Business Law (M.B.L.-HSG) and Master of International Management Programs at St. Gallen University; Partner, Homburger Rechtsanwillte, Zürich, Switzerland; Visiting Scholar and Fellow, Harvard Law School (Spring 1999). 


\section{Introduction}

This article is concerned with the workplace of many lawyers - the law office. We intend in particular to deal with questions of organization and management of an office of this kind. Are the organizational forms still customary today capable of meeting present day challenges to a consulting company of the kind concerned, effectively and actively? More specifically, most offices can still be regarded as a collection of individual experts. The joint handling of a mandate by an overlapping team seems the exception rather than the rule. In essence, each person manages only himself. One way of seeing this is as an "artist group». This form of working also closely resembles that of the lawyer's own professional image, being prepared to work to an ethical standard but, on the other hand, rarely wishing to accept additional structures, such as formal quality management, or regular feedback processes. And, as we know, this model of an office has not fared badly in past years. If, on the other hand, we look at the development in demand (increase in complex and transnational cases, internationalization of Anglo-American legal systems, growing differences in the borderline between the areas of work, etc), and the ensuing, increasing competition amongst the large offices for attractive segments of business, one can only wonder whether this form of self-reliance will still do in the future. We take the view here that law offices increasingly will have to cope with questions of professional management if they are to make headway successfully. Division of labour, team structures and co-ordination through management and management systems will increasingly impose on them the character of a "law firm»,

\section{From Law Office to Law Firm?}

Our message is that in certain selective market segments, the "traditional office» must follow the path to a law firm if it is to achieve future growth and play a relevant role in the market segments concerned. A law firm must then be regarded as falling within the category of a professional service firm (PSF) and consequently one to be conducted as a service company.

However, this also provides an opportunity for asking, what can a law firm learn from other PSFs (business consulting, marketing agencies, executive search firms, etc). This adds relevance to issues such as correct development and positioning strategy, an effective management organization, the right distribution of responsibilities for profit and loss, the formation of efficient project teams, dealing with various service cultures, etc. Since most offices are organized on a partnership basis, tension fields naturally arise, such as those between existing partner rights and the necessary organization, or between partner equality and a management hierarchy. If we now regard law firms as a specific expression of a PSF, this does not of course mean that there are no relevant features that characterize law firms only. These exist in plenty. Law firms may therefore possibly be rather different when compared with other PSFs with regard to such aspects as the importance of ethical rules, the (as yet) existing linkage to national laws, the language background to the consultancy product, the particularly strong adherence to the partnership principle, the dominance of other values, such as business consultants, the absence of horizontal mobility of experts coming in from outside because of the tradition of "self-management" (a CFO looking for a new job would hardly be the first person a law firm thinks of, and vice versa), the hitherto sparsely available range of consultancy services for law firms because of the lack of expertise, etc. Nonetheless, we feel that there is also a multiplicity of aspects in common which can be put to good use. On the assumption that the need for management know-how will drastically increase in law firms, we shall systematically consider to what exten knowledge existing in other PSF sectors could also be of use to law firms.

In this article we intend to discuss several management aspects which we feel to be particularly important, point by point. This is an initial sketch of the problem, which will be examined further in the foreseeable future. This will continue and further detail our research, teaching and training work on an important sub-area of the PSFs undertaken at the University of St. Gallen ${ }^{4}$. The comments are not based on scientific investigation, but result from professional and consultancy experience and a multiplicity of expert discussions by both authors. That PSFs are of growing interest as an object of scientific study is evident from the formation in 1999 of a new Chapter for Management Consulting at the Academy of Management. This interest in PSFs also rises from their increasing economic importance, but also from their ever more frequently occurring confrontation with management problems. A whole series of important decisions are also pending which concern the legal background to the PSF and which require a sound scientific approach to this type of service undertaking. These decisions will have a quite considerable influence on the development of individua PSF sectors and their relationship with each other. The decision of the SEC on the compatibility of auditing, consultancy and legal services will shape future strategies and the industry structure of lawyers offices ${ }^{5}$.

Consideration of the management problems of law offices is not new in itself ${ }^{\text {th }}$. Yet the development of the industry seems to be a diversion from the beaten track, lea-

Compare the overview in Müller-Stewens, Drolshammer and Kriegmeier, Professional Service Firms (Frankfurt, 1999).

Compare on this point the excellent, comprchensive study by the New York State Bar Association. «Preserving the Core Values of the American Legal Profession. The Place of Muttidisciplinary Practice in the Law Governing Lawyersm, Report of the Special Committee on the Law Governing Firm Structure and Operation (Albany, April 2000).

6 Compare for example M. Galanter and Th. Palay, Tournament of Lawyers: The Growth and Transformation of the Large Law Firm (Chicago, 1991); S. Mayson, Making Sense of Law Firns - Stralegy, Structure and Ownership (London, 1997); D.L. Spar, «Lawyers Abroad: The Intemationalisation gy, Structure and Ownershyp (London, 1997); D.L. Spar, «Lawyers Abroad: The Internationalisation R. Buchanan and J Davis, Global Restructuring and the Law: Studies of Internationalization of Le 
ding to a split into the traditional, relatively regionally oriented partnerships and the internationally operating, highly specialized law firms. Both are entitled to their existence and therefore also to a future. However, these law firms will require strong growth in management know-how if they are to make headway successfully and profitably against ever more intensive competition. In this case, the nature of strategic positioning as to whether one belongs amongst these law firms or not, rather than size, will prove decisive. This pressure towards professionalization also arises against the background of loss of income experienced by lawyers, especially in supraregional partnerships ${ }^{7}$.

We believe that partnerships of this kind must face the following challenges and developments in particular. These challenges will be decisive for the future agendas of partners in dynamic and growth-oriented law firms.

- Improving profitability of legal service providing with a simultaneous increase in client orientation, which also implies a more comprehensive integration of partia consultancy services.

- Introduction and operation of management systems, including in particular interna control, quality management and knowledge management.

- Development of vision, mission and strategies as the future goal of the partnership. This also implies statements on regional diversification and the structure of the range of services and form of diversification (internal development, alliances and mergers).

- This also includes active consideration of the effects of the Internet on law offices (on-line counselling in cyberspace, form of interaction with clients) and their distribution outlets.

- Differentiation between organizational management structures and systems (governance, process and structural organization, profit centres) ${ }^{8}$ and adherence to

gal Fields and the Creation of Transnational Arenasn (1994) 44 Case Western Reserve L Rev, S. 407448. or N.P. Vogt (ed). The International Practice of Law, Liber Americorum for Thomas Bär and Robert Karter (Basel, 1997).

According to a survey by the Nuremberg Institute for the Liberal Professions, the annual surpius per Accord in non-local partnerships in Germany (the Western states of the Federation) fell by around a lawyer in non-local part and quarter between partnerships, the situa mant offices (from 92,000 10 94,000 ). Amongst the supra-regional part due to the rise in the cost quotient (between 60 per cent and 90 per cent in relation to sometimes less than 305 for indjividual jawyers). (Lawyer density" has also increased sharply in Germany. While in 1975 there was still only one lawyer for every 2,300 inhabitants, by 1999 the figure was only the USA, there is one lawer for Germany compared wh 6l,00 in

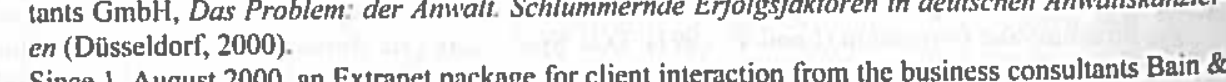

Company can be found under Bain.com on the internet. performance-oriented remuneration. Systematic consideration of questions of organizational culture and corporate identity of a partnership.

- Stronger marketing of the lawyer's services: Introduction of branding of partnerships, with appropriate budget.

- Professional, generalized upeople management", from recruitment through promotion to exit (Alumni Network, Retirement). Even if we are aware that the average size of a law office in the USA is 1.6 lawyers and that in Germany only some 3 per cent of all lawyers are active in the 25 largest offices and only 4 per cent of all professionals work in partnerships of more than 50 lawyers, we should not lose sight of the fact that this is where a major part of the fee volume of the market is earned. This applies especially to such margin-sensitive segments as M\&A, where only a few larger offices to some extent control a non-price-elastic market in principle. That is why we are not at present assuming a certain global concentration amongst offices, especially in these competition-sensitive segments. Amongst the few large international law firms, who are already intensively concerned with management questions and who now - after long hesitation - also seek advice on management matters, and the countless one-man offtces, we now frequently encounter offices of relatively medium size, but only in a few cases employing over 100 lawyers. These medium-sized economic partnerships, in particular, are facing management challenges which are very similar to those of some large law firms, since they too have to intemationalize ${ }^{9}$ - at their clientsw bidding - and must also be able to integrate consultancy services. It is for offices of this kind that this article is written.

\section{New Strategies for Law Firms}

A whole series of external developments are compelling PSFs to rethink their strategies and adapt their structures accordingly. If these developments remain unconsidered, they could threaten their very existence. If action is taken early enough, they offer new growth potential. The question is whether similar strategic challenges apply to law firms since, obviously, in recent months and years many law partnerships have been subject to a process of adjustment, sometimes dramatic.

\section{a) Diversification and Specialization}

An already very obvious trend is the globalization and consolidation of business as a result of clients cross-border activities. This opportunity of regional growth is there-

4 Compare Döser, W.H., «Rechtsanwälte als internationale Dienstleistungsuntemehmen: Das Beispie Baker \& McKenzies, in Maller-Stewens, Drolshammer, and Kriegmeier (Hrsg., 1999), S. 259-280, on the development of law offices in to international service companies. 
fore primarily due to the fact that the client's process of internationalization must be supported ("seamless service») if the client is not to be lost. Of course, international activities are also influenced by national legal systems. A stable base in the home market is therefore prerequisite for this form of expansion if the law firm is to consider additional mandates with international ramifications.

The 17 partners of the German partnership Schilling, Zutt \& Anschütz are facing a break-up of their firm. Eight partners are to join the UK firm of Allen \& Overy, the remaining nine are at an advanced stage of talks to join the US firm Shearman \& Sterling. One of the partners has expressed this as follows «it may sound clichéd but we really felt the pressure of globalization. Many of us had key experiences with clients who were happy with our work but were also asking for international advicen $^{20}$. This break-up is also an expression of the pressure on German law firms to be represented in such financial centres as London and New York in view of the dominance of Anglo-American investment banking. In some cases the pressure towards intemational representation and the development of capital market capabilities is so great that the decision is a do-or-die one.

Growth can therefore also take place with regard to the range of services offered (and the associated expertise). This can be actively achieved through a desire also to cover newly arising needs for advice. However, a certain critical size is also necessary for any additional specialization, since the law firm simply resorts to pedalling its wares. However, as a reaction diversification has spread into other legal services, because the client prefers one-stop shopping.

Virtually all law firms today are active in the area of business law, where demand has risen enormously. This results from the trend that companies today settle their conflicts through legal proceedings. The principal areas are company mergers, stock exchange floatation and capital matters, international capital markets, privatization, risk capital, corporate restructuring and co-operative agreements. In addition, however, there are many other areas of consultancy such as property rights or consumer rights. A survey by Stoller $(1999$, p. 144) revealed that law firms with more than 300 fee-earners are active in 36 consultancy areas on average. However, diversification into other "service lines" may also result in the law firm becoming to some extent a yet more widely positioned organization, in which various areas of consultancy are involved, and where for example business consultancy, accountancy, tax advice etc, are gathered under one roof. This road has been trodden by the "Big Five». Andersen Legal now employs more than 3500 attorneys world-wide - more than any other law firm. Since in the USA (except in the District of Columbia) non-lawyers are stil prohibited from owning a law firm, this expansion is occurring primarily in Europe, where a firm of auditors may also offer law services. Arthur Andersen, for example, consequently transacts this business through Garretts, KPMG as a «multidisciplinary practicen of this kind in Zurich, Ernst \& Young already employs more than 120 attor-

10 Compare Wall Street Journal Europe 31 May 2000 neys in Milan, etc. Here, too, we see the traditional service dilemma; on the one hand, clients want one-stop shopping, on the other, many of them take the altogether critical view that:

(1) the law firm is thereby no longer independent; and

(2) conflicts will arise since an auditor must report on financial irregularities while the lawyer's duty is that of confidentiality.

The "Big Five" recently received a counter-blast from the US SEC, which is requiring "auditing companies» to separate from their management consulting services because of anticipated conflicts of interest. Ernst \& Young Consulting has already been sold to Cap Gemini. KPMG Consulting is going public. After the deal with Hewlett-Packard seems to have not worked, Price Waterhouse Coopers is still debating both scenarios. Of Arthur Andersen and Deloitte \& Touche, no one knows as yet what they will do. Anderson Worldwide is shocked by the ICC arbitration about the break-up of its firm. The SEC's new guidelines on the integrity of auditors do not prohibit consulting, auditing and legal services from operating under the same roof.

However, the SEC obliges audit firms to include information about how much their auditors were paid for non-accounting work in their proxy statements. This guideline will most probably not be the last one in this matter and the future of umultidisciplinary practicesm is still in danger.

\section{b) External Growth}

Various options are available to implement diversification strategies, moving between the poles of «internal development» and (uacquisition». Internal development from one's own resources is advocated, e.g., by the unitary law office with its self-created offices in various countries, with domestic and foreign partners offering advice in different legal systems and areas.

In 1998 and 1999 in particular, the German market sought many and, in some cases, spectacular, acquisitions and mergers amongst law offices. This is clear for example, from the fact that (according to the German Lawyers Directory) by 1999 there were already seventy partnerships with more than four locations, compared with 53 in 1998. After the national and European mergers, transatlantic mergers are now awaited. Altogether, however, the merging trend seems to be fading for the time being, in terms of quantity.

In 1998, Deringer Tessin Herrmann \& Sedemund announced a merger in that year with the internationally well-known London office of Freshfields. Brickhaus, Westrick, Heller, Loeber was added in mid-2000, producing Freshfield Bruckhaus Deringer. The world's largest law office was also created with German participation. Clifford Chance in Britain initially merged with the American firm Rogers \& Wells. This association was then joined by Germany's third largest firm Piinder Volhardt 
Weber \& Axster. In mid-1999, Beiten Burkhardt Mittl \& Wegner (Germany), Pavia e Ansaldo (Italy), Moquet Borde \& Associes (France) and Mayer Lustenberger (Switzerland) then agreed on a contractually based form of co-operation. A new large law firm resulted at the end of 1999 by the merger of the German partnership Boesebeck Droste and the English office Lovell White Durant, forming Lovells Boesebeck Droste. Similarly in 1999, Schürmann \& Partner announced its association with Courder Brothers. As at 1.7.00, Haarmann, Hemmelrath \& Partner (Germany) combined with the Austrian business lawyers Hiigel \& Partmer. The Stuttgart office of Gleiss Lutz has also merged with the English firm Herbert Smith; The first German-American merger was agreed on the same date between Feddersen Laule Ewerwahn Scherzberg Finkeinburg Clemm and the New York firm White \& Case. Because of the pressure of time in particular, and the more direct management capabilities, we will nonetheless see further acquisitions and mergers in the future. For PSFs, however, they harbour a particular risk: will the necessary majority vote (often 85 per cent) be oblained amongst partners for the merger? Will partners, offices or even entire national firms not willing to merge, split off? Following the merger of the German firm of Feddersen Laule Ewerwahn Scherzberg Finkeinburg Clemm (180 professionals) with the New York firm of White \& Case (1,000 professionals in 24 countries), nine members became independent as they doubted the potential for synergies, feared domination by the US members and did not wish to work in a "law factory" which, in their view, would distance them from their clients. During the integration phase, firms are heavily engaged in their own affairs, which make it easier for competitors to lure important clients and staff away. The risk of conflict is also particularly high as various organization structures and cultures collide. And there is every probability, especially for top firms, of a certain loss of quality of service. On the other hand, alliances may be formed between several firms (local partners) conducted on the basis of co-operation agreements. This may amount to cooperation (ad hoc or ongoing) without an established structure, or co-operation may take place with or without external effects (brand name), but they can also use a joint firm as an sumbrella». Amongst co-operative structures, retaining the independence of the individual companies may be attractive. At the same time, however, it also opens up a whole range of questions requiring an answer, such as quality assurance, liability, exclusivity, profit pooling, maintaining local goodwill, name rights, etc. When independent offices co-operate on a contractual basis, however, the difficult question of rights and obligations concerning centra decisions (e.g., joint marketing or the inclusion and exclusion of co-operating partners) must be settled. How far do encroachment rights extend? In whom are they vested? Who executes them? How can they be enforced? Because of these problems, many experts regard such alliances only as a transitional model towards a merger. They have therefore declined greatly in importance at the present time. Under the name of Linklaters \& Alliance, six European law firms have combined to form Europe's largest co-operation for international legal and tax advice. Here, too, a debate is in progress as to whether the next step now is merger and who might participate, and under what conditions, and who might not. It looks as if one office after the other will be merged into Linklaters. Oppenhoff \& Rädler (Germany) has already made a start with this. We shall see which of the other five offices will follow. Undoubtedly, many partners will be lost in a process of this kind. Undoubtedly, this will sometimes be undesired; at other times, it will be a deliberate decision on such occasions on accoun of below-average performance (e.g., through early retirement).

In discussing acquisitions and alliances in the form of external growth for law firms, we must be aware of the fact that this phenomenon is more or less new to this PSF sector, i.e., little experience exists as to the actual long-term benefits. Obviously, when this kind of procedure is selected, the need for management know-how is something of an automatic consequence, both as to content and extent.

\section{c) Intensification of Competition}

A natural consequence of these developments is increasing competition between law firms. And this competition is particularly sensitive where the margins are very high, such as, for example, in the area of consultancy concerning corporate takeovers. Thi relatively non-price-elastic segment can be developed only if the firm can succeed in acquiring the best professionals for itself. However, such professionals can be retained only if the law firm can pay them accordingly. The question that therefore arises is, to what extent can certain positioning strategies and fee receipts also be transformed into above-average profitability? It is, of course, in no way the case that similarly positioned law firms are similarly profitable. Nor does this mean that clients desire for "seamless service" and "(one-stop shopping" automatically leads to greater profitability. Figure 1 provides an insight into this.

\begin{tabular}{|c|c|c|c|c|c|c|c|c|c|}
\hline & Firm & Seat & $\begin{array}{l}\text { Profil } \\
\text { per perster } \\
\text { Sminilliort }\end{array}$ & $\begin{array}{l}\text { Fee incoms } \\
\text { in } \\
\text { Smillion }\end{array}$ & $\begin{array}{l}\text { Na. of } \\
\text { parners }\end{array}$ & $\begin{array}{l}\text { No. of } \\
\text { lawyers }\end{array}$ & $\begin{array}{l}\text { Lawyen! } \\
\text { panneers }\end{array}$ & $\begin{array}{l}\text { \%, lawyer } \\
\text { outuide } \\
\text { home country }\end{array}$ & $\begin{array}{l}\text { No. of } \\
\text { countrite }\end{array}$ \\
\hline & 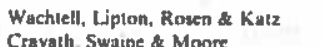 & New York & $\begin{array}{l}3.11 \\
3.05\end{array}$ & 269 & 65 & 143 & 27 & & \\
\hline & 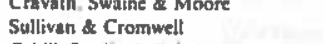 & $\begin{array}{l}\text { New York } \\
\text { New York }\end{array}$ & $\begin{array}{l}2.05 \\
1.63\end{array}$ & $\begin{array}{l}334 \\
427\end{array}$ & 119 & 434 & (3.8 3.3 & 12.6 & 7 \\
\hline & Cahill Gord in \& Reindel & New York & 1.60 & & 35 & 204 & 3.7 & 8.0 & 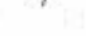 \\
\hline & Dawis Polk \& Wardwell & New York & 1.53 & 435 & 124 & 464 & 3.7 & 12.7 & 6 \\
\hline & 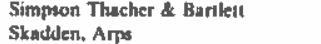 & New York & 1,50 & $\begin{array}{l}386 \\
890\end{array}$ & ${ }_{285}^{123}$ & 490 & 4.0 & & \\
\hline & 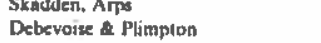 & $\begin{array}{l}\text { New York } \\
\text { New York }\end{array}$ & $\begin{array}{l}1.38 \\
1.20\end{array}$ & ${ }_{253}^{850}$ & & 1,187 & 42 & 7.6 & "t \\
\hline & Slaughter and May & London & 0.16 & 269 & 102 & 590 & SE & 13.2 & 6 \\
\hline & 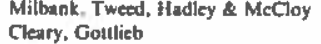 & $\begin{array}{l}\text { New Yofk } \\
\text { New York }\end{array}$ & $\begin{array}{l}1.11 \\
108 \\
\text { 1. }\end{array}$ & $\begin{array}{l}243 \\
366\end{array}$ & $\begin{array}{r}81 \\
136\end{array}$ & 372 & 4.6 & 139 & \\
\hline & Shearman \& Sterting & $\begin{array}{l}\text { Now York } \\
\text { New York }\end{array}$ & 1.05 & 染26 & 1400 & 6 & 4.9 & 290 & 9 \\
\hline & 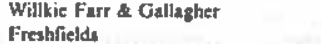 & New Yark & 0.96 & $\begin{array}{l}2177 \\
463\end{array}$ & ${ }_{279}^{108}-3-3-3$ & 376 & 3.5 & & \\
\hline & Allen \& Ovg & $\begin{array}{l}\text { London } \\
\text { Londor }\end{array}$ & $\begin{array}{l}0.93 \\
0.93\end{array}$ & $\begin{array}{l}463 \\
413\end{array}$ & $\begin{array}{l}275 \\
175\end{array}$ & 0.1136 & 6.5 & $\begin{array}{l}511 \\
345\end{array}$ & $\begin{array}{l}13 \\
17\end{array}$ \\
\hline & Weil, Gotshal Markes & New York & 0.89 & 400 & 160 & $\lim _{x \rightarrow 0}$ & 40 & 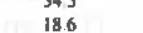 & \\
\hline & Cilitard Chance & London & OBA & 1,000 & 570 & ], 100 & 3.4 & 62.0 & 20 \\
\hline 18 & Linklaters & London & 0.81 & 479 & 207 & 1.210 & 5: & & \\
\hline \multirow[t]{3}{*}{20} & $\begin{array}{l}\text { Whitie \& Case } \\
\text { Buter \& McKenzis }\end{array}$ & $\begin{array}{l}\text { Now York } \\
\text { Chivago }\end{array}$ & $\begin{array}{l}0.077 \\
0.36\end{array}$ & $\begin{array}{l}352 \\
7{ }_{73}\end{array}$ & $\begin{array}{l}172 \\
319\end{array}$ & $\begin{array}{r}742 \\
2.330\end{array}$ & $\begin{array}{l}43 \\
44\end{array}$ & 勇9.6 & ${ }_{35}^{24}$ \\
\hline & $\sin$ & & & 8.428 & 3.999 & 16.774 & & & \\
\hline & Averale & & 1.75 & 444 & 180 & 839 & 44 & 33.1 & 14 \\
\hline
\end{tabular}




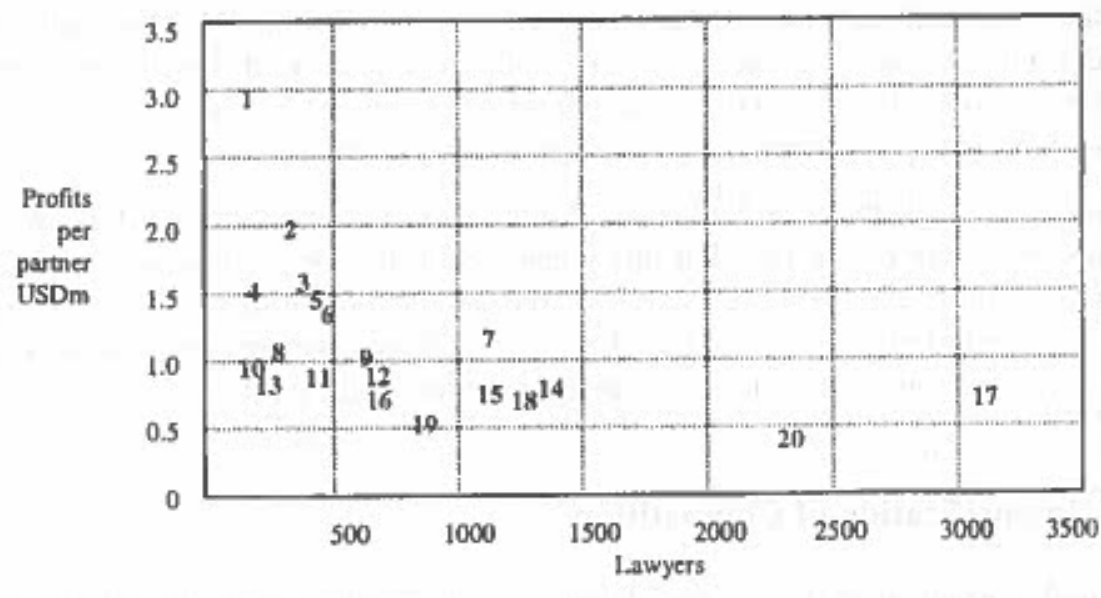

This is also graphically shown in Figure 2, where the firms from Figure 1 are transferred to a matrix. Here we can see, for example, that firms that are the most international are also the most unprofitable. This can undoubtedly also be explained by expensive office costs and the very different country margins. Nonetheless, internationalization also seems to have its price. Of course, a firm such as Baker \& McKenzie cannot be directly compared on ground of its business model with a law firm established only in New York and focusing on one service line. This draws attention to the performance of corporate management in a law firm. Law firms therefore compete not only on the quality of their consultancy services but also through the quality of their management. But this takes us back to our initial thesis, that growing offices must, on reaching a particular size, professionally come to grips with the subjects of management and organization, whether they want to or not. A law firm is a professional service firm (PSF) in the same way as larger management consultancies, marketing agencies, executive search firms, IT consultancies, engineering offices, etc.

\section{The Business Model}

Any person who runs a business in his mind thereby also adopts a "revenue mechanism?. This amounts to a model as to how it is believed that operating the business will produce profits. «Behind» a model of this kind is a system of activities which must be professionally executed accordingly. Moreover, in a small, local firm, this system of activities will look quite different and much less complex than in a larger, internationally operative and highly specialized firm of economic lawyers. To some extent, these activities can also be standardized, it should not only have a rationaliza- tion effect but also must secure preferred procedures, e.g., on grounds of quality assurance.

\section{a) Value Generating Activities}

Figure 3 shows one possibility of incorporating the more important value-added activities of a PSF into a business model. Regarding these activities standards, guidelines, handling procedures and benchmarks can be specified (by comparison with other PSFs). The service process is central to the model - the process of providing a consultancy service being specified through it, by way of example. It runs through acquisition of the project, formation of the team, implementation of the project to project completion. Every activity can now be detailed further. Under «acquisition", for example, guidelines may be issued for participation in a «beauty parade» when recruiting a mandate in competition with rivals. This service process must be equipped with four central resources:

(1) an attractive range of services on offer, capable through new, innovative products to do justice to topical developments on the demand side;

(2) staff who will be so acquired and trained that they can offer services for clients in the way required by the office's strategic positioning in the market (specialist area, regional know-how, quality level, etc);

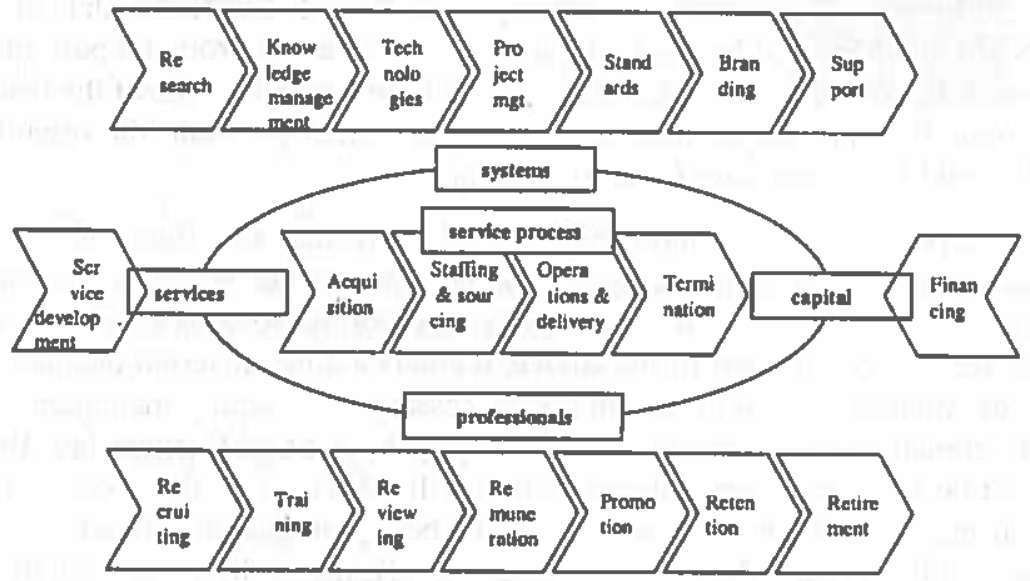

Figure 3 : The Busincss Model of a PSF

(3) systems for achieving, in particular, professionalization and standardization of consultancy services and a reduction in dependence on individual members of staff, 
(4) capital for funding the office's current activities (salaries, etc) and development (building up new offices, etc).

Capital has so far not been a relevant bottleneck for PSFs neither for law firms. Because of the diversification of activities mentioned above (assumption of internet consultancy, regional expansion, etc) and because of the explosive rise in liability risks, demand for an adequate capital basis has become topical in the meantime amongst business consultancies. This has already resulted in a number of firms being sold to highly capitalized groups (which in turn has had repercussions on the organization of PSFs). Amongst law firms, resource capital seems gradually to have gained in importance against the background of such topics as growth financing, taking equity, cash management, etc.

Systems of particular importance include pooling of individual expertise and experience through knowledge management, the securing of quality in consultancy services in hectic growth phases through quality management ${ }^{\prime \prime}$, and developing effective branding in an increasingly opaque market. Nowadays, the bottlenecks for most PSFs are their staff. This applies firstly to the acquisition of young people from the universities ("war for talents"). If they do not succeed, the growth rates now possible in the market may not be achieved (profitably). However, experienced partners must also be retained, in view of the competing dream careers in the New Economy. This market for personnel in such dynamic economic regions as Silicon Valley is particularly competition-intensive ${ }^{12}$. No less important is also the "sold boys network». Where do partners go when they leave PSFs and how systematically should the relationship with them be nurtured if they occupy important positions? Value added models of successful PSFs are distinguished by the fact that they are organized round a particular basic intention. If, for example, one takes the view that the best graduates of the leading law schools must be recruited because of one's own market position, the organizationa principle could be worganising for recruitment».

This imperative would then guide and align all individual activities and decisions of the organization. It may additionally be pointed out here that this business model stil relates purely to the provision of consultancy services. As soon as a PSF also acquires equity stakes as a counterpart for its advice, it enters a quite different business area for which other management skills are in turn necessary (e.g., equity management). Even if certain ethical questions must be answered in the case of German law firms, this trend must be anticipated since their position will otherwise be the poorer, at least on the labour market, as many competitors for the best professionals already have attractive opportunities at their disposal for achieving advantages here for their staffs. These range from job enrichment through striking leaps in income, to interesting career alternatives. Of course, not only advantages are linked with this.

"Compare L. Staub and C. Beutter, "Die ISO-9000-Zertifizierung von Anwaltskanzleien und das Anwaltsgeheimnism (1998) 12 Aktuelle Juristische Praxis, S. 1403-1409, regarding ISO certification of a law office.

12 For an impressive example, see the case study of the Venture Law Group at the Harvard Business School (Harvard Business School 2000).

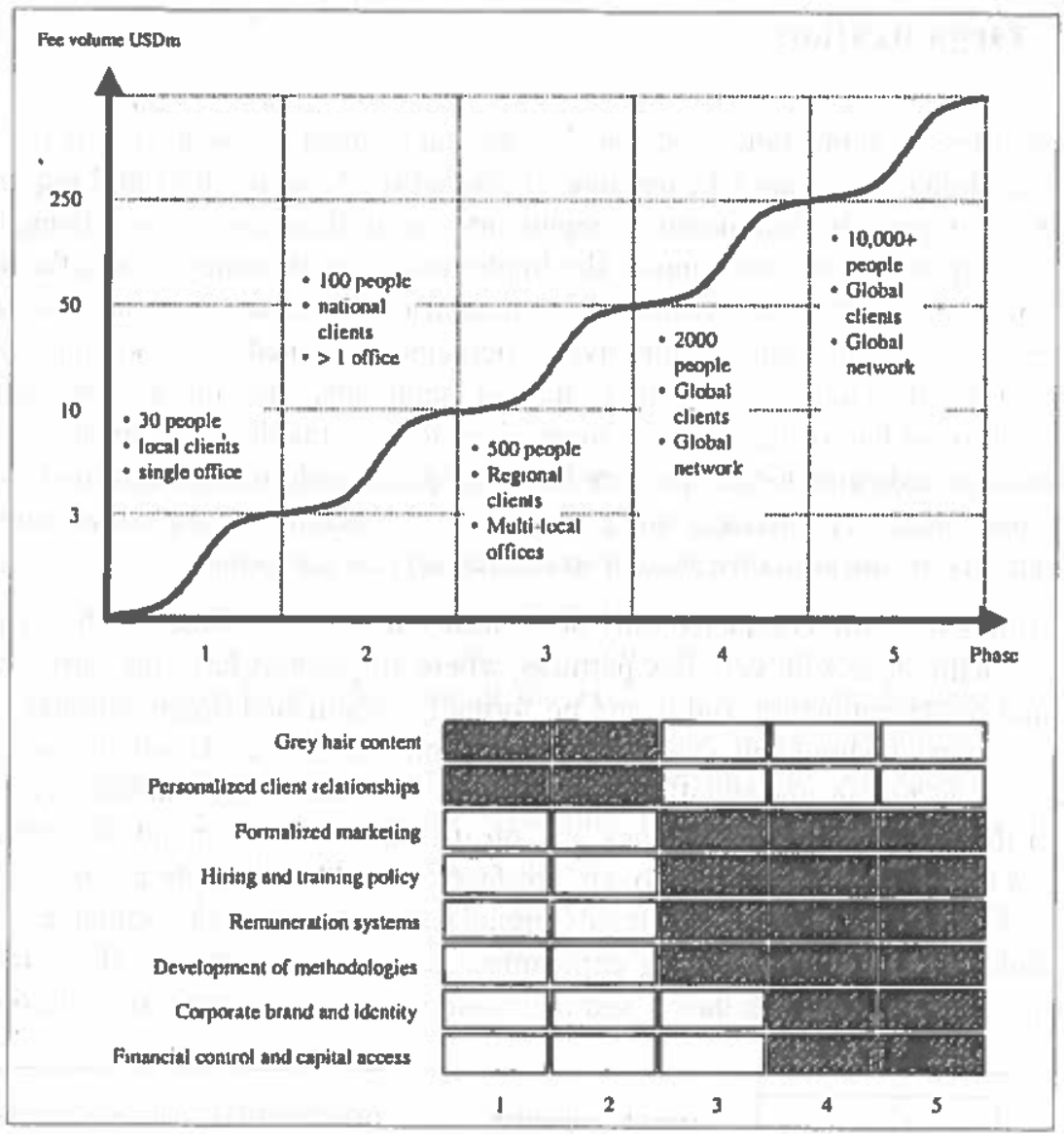

Figure 4: Dewclopment Phases and Main Attivily Shifts during the Phases (Scotr 1999)

There may, for example, be a conflict of interests (no further independent consultancy services are available from equity stakeholders)

\section{b) Shifts of emphasis in growth}

The importance of individual value added activities in the process organization of a PSF changes along the growth path of a PSF. Figure 4 makes this clear through a phase model. A smallish consultancy with less than 30 fee earners often only has local clients and a single office. What is usually sold here is the experience of the founders and very personal client relations are pursued. The subject of capital access and branding becomes relevant only in phase 4 , when the PSF starts to align itself globally. Does this model apply to law firms as well? Once we disregard threshold values in employee figures, this seems to be the trend. Law firms already exist in class 4 , for example, with 1,000 professionals, etc. 


\section{Organization}

A law firm's organization must, on the one hand, meet the objective it has set for itself. In doing so it must take account of professional peculiarities and requirements which are in part also laid down by regulators - as in the area of law offices. In addition, the organization must support the implementation of strategies and the achievement of goals. On the other hand, a PSF must also be able to offer the organizational framework in which strategic initiatives - perhaps unplanned - can adequately unfold in order to develop new services, market segments, etc, on a corporate basis. Although most law offices portray themselves to the outside world as an association of attorneys dedicated to the "partnership principle», modern organizational structures have made headway internally since the 1980s - especially amongst law firms on the US pattern - of the kind observed in structured service companies ${ }^{13}$.

The firm is then still conducted only on a partnership basis. Offices of this type are in contrast with those with very few partners, where all partners have the same co-operation and co-determination rights and no formally established organizational structure exists (as yet). It should also be noted at this point that the way in which law firms are organized is not insubstantially influenced by «in-house legal departments», with which the offices acompete». They are, on the one hand, their indirect competitors and, on the other hand, frequently an interface - and consequently co-operative partners - with the client. They are already organized according to the principles applying in "their" companies. "Auditing companies» are also subjected to these reciprocal effects. The way in which they - and their associated (dlaw practices» - are organized

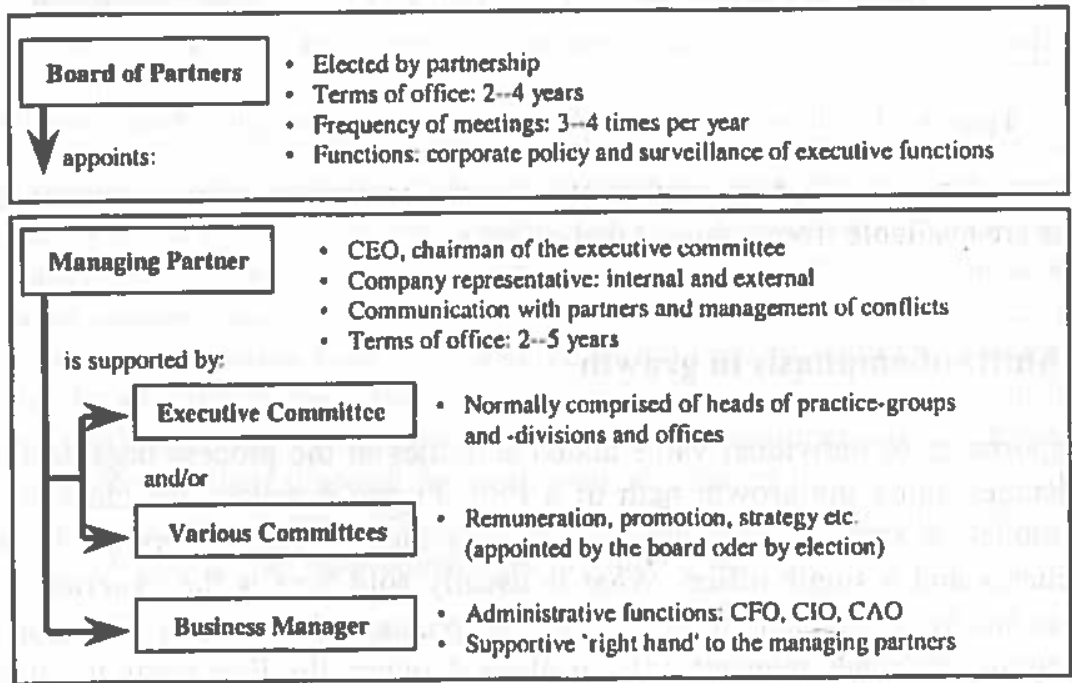

Figure 5. Development phases and main activity shifts ind uhe phase (Scoll 1999)

13 Compare P. Hardt, Organisation Dienstleistungsorientierter Unternehment (I996). has a not insubstantial influence over the organization of law firms. The choice of organizational form is not, of course, determined in this case only by business considerations but - as Drolshammer (2000) shows in this issue, with the Big Five as an example - quite appreciably also by legal and tax aspects. The fact, too, that business consultancies such as McKinsey or the Boston Consulting Group advise law firms on strategy and organizational matters results in the experiences of their own and other PSFs being incorporated in the law firms.

\section{a) Governance}

Figure 5 shows the more important elements of PSF management structure, as found also in law firms. The investigation by StoBer (2000, pp. 105 et seq.) showed that there were two different types of organization in law firms. With the "chairman models the hierarchy is headed by a senior partner. He is assisted by an executive committee which is in turn supported by a strategy committee. The important entrepreneurial decisions are taken here. Members of the executive committee include selected partners in the firm. A managing partner chairs the executive committee, and also undertakes primary management duties. He is responsible for the back-up office, office management, IT matters, training, marketing, finance, etc. Under the "Triumvirate model» the organization is headed by at least three persons: the senior partner, managing partner and finance partner. In large law firms, non-lawyers may now also be found in the information technology and finance divisions, and also specialists heading these functions.

\section{b) Management dimensions}

The structural organization, and the interplay occurring within it between the individual management dimensions, is to some extent the "core" of a PSF. Here, how it functions, what is feasible and what is not, how powers are distributed, etc, becomes most clearly evident. It is thereby the expression of the PSF's culture. However, it also reveals existing management capacities: to what extent competencies are urigidlys arranged, or if people are able - on the basis of action principles - to solve questions of competency flexibly and to some extent independently of the individual interests of the management levels (so that sub-optimization effects are avoided), as more readily meets the requirements of a PSF. A PSF's organizational structure is often only a necessary point of departure which must be kept fluid - albeit in established form. Principles of this kind may for example relate to a balance of interests to be aimed at by all, associated with various organizational dimensions and responsibilities, or a principle is laid down as to what is meant by a level-related distribution of responsibilities. Principles of this kind should then prove clarificatory and guide action in a specific case. The first dimension along which organizational design arises in a PSF is the so called uservice Une», i.e., the various kinds of services offered by a 
PSF, which are broken down into specific organizational areas on the basis of anticipated specialization advantages. The reason for this delimitation may be the various expertises that the business requires. The reflected client segmentation to which this often gives rise should not lead one to believe that the attitude adopted towards the client is therefore suitable. A client who may perhaps require several of these expertises will usually have one contact point with this consultant and will expect his needs to be met in a co-ordinated and integrated way. The broader the spectrum of services of a law firm, the more varied will be the cultures in the individual service lines. The type of person alone will mean that conduct and practice will differ greatly as between a litigation department and a corporate finance department. The eamings mechanisms and business practices also show major differences. Since strategy, structure and culture must be co-ordinated, more care will have to be taken, as competition increases, that this remains the case. "Bowiquising» of law firms in this way is already clearly evident, although it must be said that many legal specialist areas are unsuited to being adopted as own service lines as well. In the course of further development, certain market strong-points will then emerge with most PSFs. From a particular point, it then becomes worthwhile in this case as well to divide up organizations

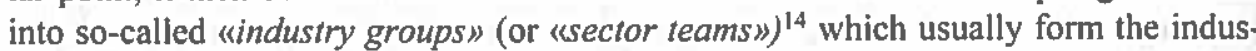
trial strong-points with which the PSF is engaged. From this one expects a more expedient and pertinent processing of client requirements as a result of better knowledge of the industry. This can then be taken yet one stage further, by setting up ukey account management" for a particularly important client, e.g., in the form of a "customer relations managern or a corresponding team, so that there is direct 1:1 competency in the PSF (in the form of a partner or team of partners). In business consultancy practice it is evident that this organizational dimension is increasingly being used proactively. The way in which this is done is to process an industry from which a high demand for the firm's specific consultancy services is expected (e.g., on account of its deregulation or liberalization), even without specific mandates, studies are worked up and potential clients are approached with the firm's own ideas for improving performance. To guide the firm's own client portfolio, a list of target clients» may also be drafted and then actively worked on. In this way, it is hoped to get away from sometimes luxuriantly originating client portfolios where often any kind of conceptual basis is lacking and where there is therefore little potential for synergies. With the increasing number of international offices, the challenge of international integration of individual local industry groups then of course arises. The question must be tackled in what form such global, virtual teams can be integrated and to what extent this is in fact possible ${ }^{15}$. Experience shows that the maximum that can be achieved is one continent (e.g., "European Telecommunications Group»). With this second management dimension, clear differences undoubtedly exist amongst law firms, at least in their

14 The expression upractice group" is used disparately for both industry and for services.

Co-ordination and management of such virtual teams is one of the greatest management challenges of our time. See on this point for example, J. Lipnack and J. Stamps, Virtual Teams (John Wiley \& Sons, New York, 1997). present form. While an active and commercial approach by lawyers to clients is (as yet) sometimes even prohibited (e.g., so-called "cold-calls" may not be made), this recruiting approach is also not to most lawyers" taste, either. It is considered obtrusive and conflicts with the duty of reticence inherent in the profession's concept of itself. Many lawyers are therefore already irritated when competitors mention selected clients as a form of publicity. With the second management dimension, the organization is faced with the question of how these two dimensions can be related to each other. Here, there are two essential options: either the two sub-organizations are allowed to run side by side; or the two dimensions are inter-related through a matrix. In the former case, an employee will be assigned to only one of the two dimensions. In the latter case, there is a double assignment. Of course, the two dimensions again meet at the top management levels, at the latest, in the former case. And then such critical questions arise such as «to whom should earnings be ascribed?»; «who can dispose over staff, and how?»; or whow greatly is a partner of a PSF assessed in line with the degree to which his own area is committed?"

In the latter case, such questions are already entered into the matrix. Here, again, a distinction must be made between two possibilities. If the two dimensions are equivalent in management terms, every question must be settled (non the spot» at the point where the expression of the two dimensions overlap in the matrix. This increases the conflict sensitivity of the organization. This «pure matrix» can therefore be regarded as a relatively laborious organizational form. The number of meetings usually increases as a result of the growing need for clarification; conflicts of authority again arise between the two dimensions. If the pure matrix is not applied, then one of the two dimensions predominates. This is generally the historically developed dimension of the service lines. The heads of these areas have powers of direction over all staff assigned to their service line. This becomes relevant, e.g., when "staffing" the project team. Each employee is in fact also allocated to an industry group. However, the head of the industry group only co-ordinates. Attempts are made to motivate in the direction of industry groups extrinsically, by means of inducements that subsequently play a role in the assessment and remuneration of staff.

A third management dimension still to be found in globally operating PSFs is the regions (also known as «theatres»). The organization may therefore be divided, e.g., into three organizational units - America, Europe and Africa; and Asia and Australia. With these regional differentiations, geographical and cultural proximity of course play a decisive role. The regions often play the role of national companies from which an international PSF has generally proceeded as an excrescence, which seen from a higher level, must be optimized. One therefore wonders at what level the central value added processes operate. What percentage of staff should be allocated to the projects at European level, or should staffing be global? Training is generally a function undertaken both locally and globally, while recruiting is primarily undertaken locally. In addition to these three management dimensions, a fourth could be said to exist: the management of equity stakes acquired. To retain good partners and to keep a foot in the door of the New Economy (since it is not possible at the start to meet the high fees 
demanded), they may sometimes also be prepared to accept shares instead of fees («taking equity»).

\section{c) Responsibility for Results and Distribution of Power}

In large PSF's it is now almost commonplace for "profit-and-loss-responsibility" to be associated with an organizational dimension, which substantially influences the way the PSF functions. The reasons for this are many. First of all, there is a desire to foster entrepreneurship as a basic attitude, by decentralising responsibilities and powers. The intention is to achieve greater identification with one's own business, with such consequences as improved cost consciousness, greater market awareness, more competition between business units within the partnership, shorter decision taking paths, reinforcement of specialization, fewer central functions, etc. Negative effects may be over-specialization, de-globalization and sub-optimization. Area egotism may distort identification with the organization as a whole. As to how a suitable «geometrym is arrived at for P\&Ls, there is no simple answer. How, for example, does one discover from what size it is worth to further split down an independent unit further? Attempts may be made to iron out the said disadvantages of P\&Ls by forming counterweights to them. For example, competence centres may be formed for central functions (e.g., research and development) diagonally across P\&Ls. Or, because of the problems in allocating fees to the matrix dimensions, a deliberate attempt is made to go by the matrix overlaps and their hopefully productive conflicts, by introducing (double-counting" of projects amongst both service lines and industry groups. However, so that a completely distorted picture is not produced, a clear allocation mus again be made at consolidation point at the latest. A third counterweight to the P\&Ls could be to control the income of the industry groups. A further instrument is the remuneration system where bonuses are ascertained as a mix of P\&L results and correspondingly highly weighted firm's results. Because of the conflicting centralized and decentralized interests deliberately imported into a matrix, it is especially important for a PSF to have an instrument at its disposal to measure performance, so that the desired equilibrium can be ascertained as precisely and rapidly as possible in order to take counter measures where necessary. It must be remembered that the weightings do not arise simply from the structural rules but that P\&Ls are also culturally established and influenced. If P\&L ownership is regarded as a "paradise on earth" in a PSF, it must be possible for substantial symbolic and power-political counterweights to be created amongst the other organizational dimensions, if the principal of equilibrium is applied.

In order to bypass the matrix somewhat, attempts can also be made in large international organizations to merge various P\&Ls into one account. This can be done, for example, by skirting the key accounts, i.e., the manager responsible for this account has his results measured with certain clients. In other words, in a two-tier process of this kind, the bookkeeping P\&Ls are consolidated at account level. Here, too, P\&L responsibility again exists. «Combinations» of this kind can also be created in relation to client groups or clients particular problem areas. However an organizational structure is arranged, it must be tested against the risk of new business areas being overlooked because they fall between two existing organizational units. An example of this is the very late recognition by most of the established consultancy institutions of the importance of e-business and the new competitors emerging here. Another important question is how a P\&L unit newly delimited at international level can be raised to a critical size in the local companies concerned. Until it is large enough, it will usually still be grouped together with other P\&Ls. It must also be remembered that frequently there are accounts that are global by nature, while others must be kept purely local. If, for example, the large pharmaceutical companies are to be assisted with advice, it is certainly worth setting up a "global market unit» whose objective is to create a profound overview of this industry, coordinating the offering internationally developing capabilities world-wide, etc. In other cases, it is perhaps more effective for the client to «belong» to local units.

\section{d) Culture}

An important element in the organization of a law office is also its culture. It imbues the daily conduct of business and also expresses the power relationships created by the formal structures. This culture can be grasped only with difficulty. It is subject to change but the consequences of such changes are hard to forecast. However, since in a "people business", which the lawyer's work is, the culture is of prime importance, the management must also take due account of it in a law firm, where the partners must work over 80 hours a week if the work is to be properly stage-managed to keep the staff «happy». But what would an international partners meeting be without professional stage management?

One aspect of culture management is for example dealing with symbols. This includes the choice of the building, its appearance, the demonstrated value of modern technology, the customary attire, etc. Status, too, is also frequently expressed through symbols. But rituals are also an element of culture. For example, the daily gourmet buffet in the office at 9 p.m. gathers stabilising momentum, in the same way that the unwritten rule of "working into the night" can itself become a ritual

Language is frequently also a clear expression of a particular culture. What concepts are used in argument? What is meant by such commonplace terms as, for example "loyalty" or "performance»? Does one demonstrate one's world citizenship through a particular density of Anglicism in one's discourse. Who is usually the first to speak? etc. Yet the implementation, too, of the «one firm approach" aimed at by many internationally operative PSFs, (i.e., how a firm "from the same mould" acts worldwide) is very largely determined by the culture, by the corporate identity, and by the shared values of the office. Where offices are merged, the culture often becomes a critical success factor in successful integration. When one looks into the reasons for a failed 
merger, apparently unbridgeable cultural differences are frequently mentioned as an important cause. The «culture clash» when two organizational cultures impinge, frequently ties down enormous resources that may result in the loss of important performers.

Even if culture is a relevant factor of organization in all PSFs equally, it may be assumed that one or more of the core values of a law firm's culture will differ appreciably from that of other PSFs. This is partly due to the fact that the lawyer's profession tends to attract a certain type of person. But to some extent cultural differences also arise through the specific nature of legal work and through the social imprint acquired during legal training and professional experience already gained. These cultural differences are also evident in the multidisciplinary practices of the Big Five and are not infrequently the source of management problems. However, in terms of existing cultural diversity, they offer an opportunity that should be seized, which again is a task of management.

\section{Summary and Prospects}

Lawyers are not fee-takers but must also think and act entrepreneurially - of course in addition to their professional work. Management know-how and systems will therefore become an indispensable component of any law firm. This development wil undoubtedly not affect all types of law firms in equal measure, but is bound to emerge especially in certain internationally aligned client segments and particularly marginsensitive service segments. It is important, in any case, that we are aware that two different business models and consequently two different organizational models are concerned ${ }^{16}$. This requires a clear strategy decision, as it gives rise to many consequences with regard to managing and organising a firm of this kind. The local firm is therefore no more of an uend-of-line model» than the traditional one-man-office, and it will still remain the culturally deferred workplace for many lawyers since in thei view the larger firms are merely ulaw factories». Since profitability and quality assurance are also of course an aspect of management, ongoing standardization of the processes $^{17}$ in law firms can therefore not be put off indefinitely. The risk is also that

16 If we use Mintzberg's organizational typology (H. Mintzberg, Die Mintzberg-Struktur: Organisationen Effektiver Gestalten (Landsberg, 1992)), the international law firm could well be described as a "professional bureaucracys and the local firm as an coperative law firm could

17 Standardization plays an appreciably greater role in the legal profession having regard to the standardization of knowledge. Because of their professional status and the consequently extensive training the necessary co-ordination amongst professionals is generally based on the standardization of knowledge. The lawyers professional tradition also implies an entitlement to autonomy and self determination in working Lawyers may thereby attempt to minimize the influences of others on the work. However the global activity of international law firms is increasingly requing professust also to work in teams in order to offer comprehensive multintion saves. Tequing ping reques of bureaucratization, in the form of over-standardization, to the detriment of customising - the central success factor of any consultancy work. Maister in 1993 pointed out that traditional management principles such as standardization and monitoring were particularly problematical and extremely sensitive when applied to uprofessional servicesy. The strong external orientation of the business would also always additionally complicate subordination to internal management and organizational mechanisms. The sketchy approach in this paper towards the phenomenon of the development of law offices from one-man firms and local partnerships into internationally active law firms has, in our opinion, demonstrated that a thorough scientific and interdisciplinary dialogue has become necessary. We therefore advocate at this point that:

(1) Universities decide in their business economics and law departments to tackle the PSFs in their research, since they have become an important factor in every national economy and display many noteworthy features ${ }^{18}$. So that this is done in a problem-related way and PSFs may also benefit from the results, e.g., in the form of tailormade training and research projects, PSFs should be committed to selected universities. This can be done, for example, by sponsoring professorships, as in other new industries (trade, media, etc).

(2) The legal management and general management of law firms must be integrated. For this purpose, the special features of law firms must be identified so that proper account can be taken of them in structural models. Building on this, an area of research and learning should be developed in which, apart from professionals, the "organization of professionals" should also be covered in an inter-disciplinary manner. The considerations set out above are primarily of an intuitive nature. They are based on many assumptions, which can also sometimes undergo sudden change and then initiate entirely different consequences. A comparative minor example of this is the new attitude of the SEC, which initially made the Price Waterhouse Coopers merger probably the last event of its kind and which practically turned the «multidisciplinary practicen, which was still so much in vogue a few months ago, into an end-ofline model overnight. However, the trend towards increasing use of legal services may well subside, as people again learn how to solve their own conflicts. Or even more generally, we could see a turnaround in the economic approach to motivation in society, since a future elite may no longer be willing to accept a heavy loss of meaningfulness as the price for long working hours and extreme prosperity. An appreciable, lasting collapse of the stock markets or the prevalence of social differences could be the trigger. It is not our aim to paint a black picture. But such alternative scenarios should never be lost from sight since nowadays they become reality at the

not oniy close co-operation but also ongoing dialogue. Yet this trend towards co-operation must in turn be secured by certain process and quality standards.

- Knowledge transfer may of course moreover prove useful for future-oriented management of industrial companies. PSFs have substantially more comprehensive experience of managing decentralized and networked structures than exists in industrial undertakings. The use of cintellectual capitals is also relatively advanced in PSFs. 
most varied points of our world more frequently than we are perhaps able or willing to see.

\section{Bibliography}

DOSSER, W.H., "Rechtsanwälte als internationale Dienstleistungsunternehmen: Das Beispiel Baker \& McKenzies in Müller-Stewens, Drolshammer, and Kriegmeier (Hrsg., 1999), S. 259-280

J. DROLSHAMmER, "The Future Legal Structure of International Law Firms - Is the Experience of the Big Five in Structuring Auditing and Consulting Organizations Relevant?", below, p. 713.

M. GALANTER, and TH. PALAY, Tournament of Lawyers: The Growth and Transformation of the Large Law Firm (Chicago, 1991)

P. HARDT, Organisation Dienstleistungsorientierter Unternehmen (1996)

Harvard Business School (eds), Venture Law Group, Case Study, 9-800-065 (2000)

Kienbaum Management Consultants GmbH, Das Problem: der Anwalt. Schlummernde Erfolgsfaktoren in deulschen Anwaltskanzleien (Düsseldorf, 2000)

J. LIPNACK and J. STAMPS, Virtual Teams (John Wiley \& Sons, New York, 1997)

B.R. LOWENDAHL, Strategie Management of Professional Service Firms (Kopenhagen, 1997)

D.H. MAISTER, Managing the Professional Service Firm (New York, 1997)

H. MiNTZBERG, Die Mintzberg-Struktur: Organisationen Effektiver Gestalten (Landsberg, 1992)

S. MAYSON, Making Sense of Law Firms - Sirategy, Structure and Ownership (London, 1997) G. MUller-Stewens, J. Drolshammer and J. Kriegmeier (eds), Professional Service Firms (Frankfurt, 1999)

G. Müller-Stewens, J. Drolshammer and J. Kriegmeier, «Professional Service Firms Branchenmerkmale und Gestaltungsfelder des Management(s) in Müller-Stewens, Drolshammer and Kriegmeier (eds) (1999) S. 11-153

New York State Bar Association, «Preserving the Core Values of the American Legal Profession. The Place of Multidisciplinary Practice in the Law Governing Lawyersm, Report ofthe Special Committee on the Law Governing Firm Structure and Operation (Albany, April 2000)

M.C. ScotT, The Intellect Industry - Profiting and Learning from Professional Services Firms (Chichester, 1998)

L. STAUB and C. BEUTTER, «Die ISO-9000-Zertifizierung von Anwaltskanzleien und das Anwaltsgeheimnis" (1998) 12 Akruelle Jurisrische Praxis, S. 1403-1409

D.L. SPAR, «Lawyers Abroad: The Internationalisation of Legal Practice» (1997) 39:3 California Management Review, S. 8-28

C. STOLLER," Mega-lawyering in Europa» in Zum Wandel der englischen Anwaltspraxis (Frankfurt usw)
D.M. TRUBEK, Y. DeZALAY, R. Buchanan and J. Davis, "Global Restructuring and the Law: Studies of Internationalization of Legal Fields and the Creation of Transnational Arenasy (1994) 44 Case Western Reserve L Rev, S. 407-448

N.P. VOGT (ed.), The International Practice of Law, Liber Americonum for Thomas Bär and Robert Karrer (Basel, 1997) 